\title{
Enlightenment of Cognitive Approach to Japanese Teaching
}

\author{
Liming Wang \\ College of Foreign Languages, Bohai University, Jinzhou, 121013, China \\ 2860333710@qq.com
}

Keywords: cognitive approach; Japanese teaching; enlightenment; theoretical basis; teaching process

\begin{abstract}
The extensive communication between China and Japan has promoted the development of Japanese language teaching. Many achievements have been made, and many problems have arisen, such as the backward teaching mode. Cognitive according to the cognitive law of students teaching, adapt to the cognitive process of foreign language learning, is conducive to cultivating interest in learning and enthusiasm, and cultivate creative thinking. Based on the cognitive theory, this paper analyzes the cognitive process of foreign language teaching and puts forward the enlightenment that of cognitive method to Japanese teaching. The specific revelations include: advocating the student-centered teaching mode, strengthening the cultivating and training of the ability of using the language, and comprehensively improving the four skills that listening, speaking, reading and writing. In the daily teaching focuses on cultivating students' autonomous learning ability and fully plays the role of Chinese knowledge in Japanese teaching.
\end{abstract}

\section{Introduction}

The cultural exchanges between China and Japan have a long history and Japan is deeply influenced by Chinese culture. In ancient times, due to China's political, economic and cultural are relatively developed, a large number of Chinese culture lost to Japan, Japan has undergone a comprehensive absorption to digestion and transformation of Chinese culture, and gradually created a Japanese national characteristics. In modern times, after the Meiji Restoration, Japan embarked on a capitalist road, the trend of cultural exchanges between the two countries is more of China to learn from Japan, during this period of Sino-Japanese cultural exchanges and China's Revolution and the New Culture Movement Have a close relationship. At present, the rapid economic and social development, the two countries more extensive exchanges, involving economic cooperation, scientific and technological exchanges and cooperation, cultural exchanges and cooperation, military exchanges and cooperation. Sino-Japanese communication requires Japanese-language specialists. After the reform and opening up, many colleges and universities set up the Japanese major, Japanese teaching has achieved great success, cultivate a large number of Japanese talents for China's modernization and the development of Sino-Japanese exchanges made a great contribution.

Japanese teaching has made great achievements at the same time; there are many problems, outstanding performance for the teaching mode backward [1]. Teaching model is a certain teaching theory or teaching theory, under the guidance of a more stable structure of the teaching activities and activities of the framework of the program. As a structural framework, it highlighting the teaching mode from the macro to grasp the overall teaching activities and the internal relations between the various elements and functions; as the activities of the program highlights the orderly and operable teaching mode. In the traditional teaching mode, the teacher is the center of the teaching activity, the main body of the teaching activity, the educator of the knowledge, the student is the recipient of the knowledge, the media is the teaching tool, the teaching material is the teaching content, the student achievement is the teacher's teaching Level, classroom teaching as the main environment for teachers to perform the stage. As a cognitive subject, students are always in a passive acceptance position in the whole teaching process. Learning initiative is ignored, which is incompatible with the requirements of modern society for talent cultivation. It is imperative to change the traditional teaching mode. 
Cognitive law originated in the United States in the mid-1960s, as the opposite of hearings. In the 1960s, due to the rapid development of science and technology in the world, fierce competition in the fields of politics, economy, military and science and technology required a large number of high-level talents who could directly carry out international scientific and cultural exchanges. In the United States, the basic theories of psychology, pedagogy, and linguistics have also developed greatly. In order to create a new way for the creation of new teaching methods, the new teaching methods are becoming more and more demanding. Of the foreign language teaching system provides a solid foundation, cognitive method will come into being. Cognitive language teaching principles include the following aspects [2]: student-centered; understanding of language knowledge and rules based on the training, emphasizing meaningful learning; listening, speaking, reading and writing go hand in hand, comprehensive development; the use of mother tongue ; The error analysis and grooming; extensive use of visual teaching methods and audio-visual teaching methods, foreign language teaching scenarios and communication. Based on the cognitive method, this paper provides a new teaching mode and solution for Japanese teaching.

\section{Cognitive Approach of Cognitive Approach}

Include the basis of psychology and linguistics.

(1) The basis of psychology. The basis of psychology is Jean Piaget's cognitive development theory. Cognitive development refers to the course of individual's cognition of the affairs and the way of thinking and ability expression in the face of the problem context, and the course of change with age. The structures of development include schemata, assimilation, adaptation and balance. Among them, the schema has the function of arranging, classifying, transforming and creating the object information so that the subject can adapt to the environment effectively. Assimilation is the process of the subject integrating and integrating the information in the environment into the existing cognitive structure. To adapt to the schema of the subject can not meet the requirements of the object, it is necessary to change the original schema, or create new schematics to adapt to the needs of the environment process; balance the original cognitive structure; , Is the main body of the development of psychological motivation, is the main trend of active development. Through the interaction of assimilation and adaptation meet the environmental requirements of the dynamic equilibrium.

Cognitive development theory has an important impact on contemporary education and teaching, and has important enlightenment and significance for contemporary education. In the contemporary education and teaching, the goal of education should focus on improving the students 'understanding of knowledge; teaching content should be applied to the level of students' cognitive development, and constantly break the existing balance of students to establish a new balance; teaching students should pay attention to individual differences Should pay attention to the cultivation of students' ability of self-regulation; teachers should establish a new concept of education.

(2) Linguistics basis. The basis of linguistics is Avram Noam Chomsky's transformation-generating grammar rules. Language is subject to the rules of the system, people have a natural language acquisition mechanism and language skills. Human using language is not by mechanical imitation and memory, but continues to understand and master the language rules, and creative use of the language process. Syntax of the transformation syntax is shown in Fig. 1.

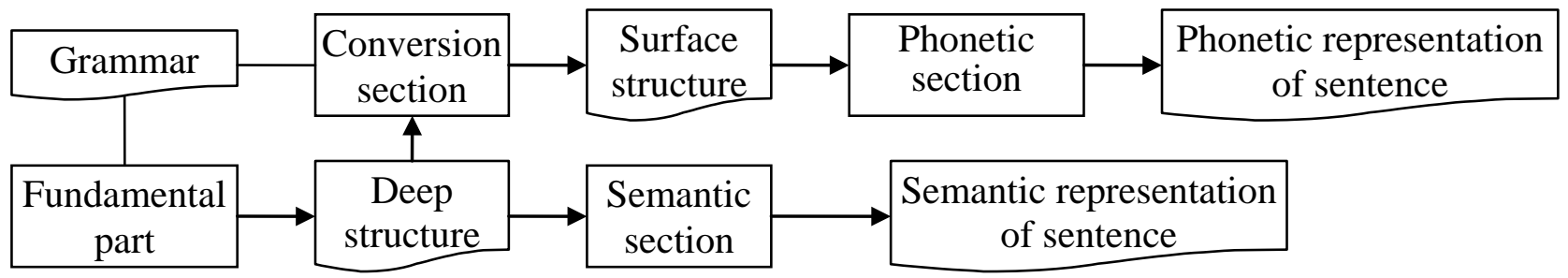

Fig. 1. Process of transformational generative grammar 
The syntax shown in Fig. 1 mainly consists of two parts: the foundation and the transformation. The underlying part generates the deep structure. The deep structure obtains the surface structure through transformation. The semantic part belongs to the deep structure, and makes the semantic explanation for the deep structure. The speech part belongs to the surface structure and makes the phonetic explanation for the surface structure.

Transformational generation theory holds that human beings have innate linguistic talents and can create infinite sentences through limited lexicon. This point of view on the interpretation of human language learning ability and help learners to learn a foreign language provides a strong basis [3]. 2. Transformational Generative Grammar puts forward unique ideas for language teaching. When designing textbooks, sentences with the same deep structure are arranged together, so that some ambiguous sentences can be well explained by analyzing the deep structure of sentences. Conversion rules can also help teachers to teach complex sentence structure. Transformational Generative Grammar provides a new approach to stylistic analysis.

\section{Foreign Language Teaching Process based on Cognitive Approach}

Foreign language teaching process is divided into three stages based on cognitive approach, as shown in Fig. 2.

\begin{tabular}{|c|}
\hline Understanding language \\
\hline Cultivate language comprehensive ability \\
\hline$\downarrow$ \\
\hline Use language \\
\hline
\end{tabular}

Fig. 2. Foreign language teaching process based on cognitive approach

(1) Understanding language. To enable students to understand the content of teaching teachers, or understand the language materials and language rules of meaning, composition and usage. Understanding is the basis for engaging in language activities, all language activities are based on understanding. Cognitive method requires students to understand the new language rules, not by the teacher's explanation, but in the guidance and inspiration of teachers, students themselves to find grammar rules.

(2) Cultivate language comprehensive ability. Learning foreign language, not only requires students to understand the language knowledge and language rules, more important is to develop students to use language integrated ability. This comprehensive capacity can only be achieved through conscious, organized training and training. Language comprehensive ability is built on the basis of good knowledge of the language, there is no good basic knowledge of the language can not have a good integrated language skills.

(3) Use language [4]. This stage of the teaching task is mainly based on student self-learning, training, "listening, speaking, reading and writing" language use. Special attention should be paid to the cultivation of learners' communicative competence, that is, the ability to cultivate creative communicative competence after graduation.

\section{Enlightenment of Cognitive Approach to Japanese Teaching}

Japanese teaching is the practice of language teaching, due to the limitations of traditional teaching concepts and language environment, rigid teaching methods, students lack initiative, awareness of foreign language teaching for Japanese language teaching as follows:

(1) To promote student-centered teaching model [5]. Teachers in accordance with the needs of students develop teaching objectives and content, by students to participate in the completion of the entire teaching activities, students as the main participant. In the knowledge and skills on the basis of impartial, focus on knowledge of horizontal and vertical integration, so that students receive knowledge, enhance learning interest, create new thinking, improve the ability of integrated 
language application, exercise analysis and problem-solving skills, improve self-learning And cooperative learning ability. Change the traditional classroom communication power of space, to determine the students in the learning process of the dominant position, emphasizing the two-way classroom and autonomy. Teachers are "the cultivator of student consciousness, the analysis of student demand, the decision-maker of responsibility transfer, the negotiator of teaching method and the equal learner". The students are autonomous, participant, explorer and creator. In the process of teaching, teachers from the "understanding of students, respect for students, service students, enlighten students and motivate students" and other five aspects can be more satisfactory results.

(2) Strengthen the ability to use language training and training [6]. Learning language is not a process of imitation and memory, but a creative activity, with limited rules to create infinite sentences. Linguistic competence refers to the ability of a person to recognize and understand sentences. It also includes the ability to summarize linguistic materials, derive linguistic rules, and generate sentences that conform to rules. The basic purpose of Japanese teaching is not to impart grammar knowledge, but to develop students' ability to use language; language ability is the premise of language use. Japanese has its own characteristics, it is necessary to pay attention to whether the grammar, but also pay attention to the language of acceptability and decent. It is necessary to meet the grammar, but also in line with social norms. At the same time, we should pay attention to written and spoken language of the different expressions. In the study and use of Japanese knowledge, we should pay attention to learning in different contexts in different languages, according to oral communication or written expression to choose a different form of expression, to avoid the written language is too colloquial, oral expression of excessive formalization and excessive Solemn phenomenon, to avoid communication errors.

(3) Fully enhance "listening, speaking, reading and writing" four skills. The comprehensive principle of language teaching not only emphasizes the integration of teaching methods, but also emphasizes the integration of language skills. "Listening, speaking, reading and writing" four skills are relatively independent, but also linked to comprehensive development. Even one-way skills, teachers should reflect the comprehensive language skills. Listening and reading process is actually the learner from the outside and within the acquisition of language knowledge of the input process, speaking and writing is the knowledge of learners from the inside out of the output process. Language teaching must focus on input, absorption and output of three links, so that students learn new knowledge into the long-term memory system, into the existing knowledge structure, the formation of their own language generation system. "Listening, speaking, reading and writing" to enhance, not only embody the language teaching from the overall integration of the four skills of the overall language law, but also to enrich the diversity of classroom teaching, to avoid a single language activities generated by the Boring and tired, so as to maintain the lasting interest of students.

(4) In the daily teaching focus on cultivating students' autonomous learning ability. Autonomous learning is a kind of modern learning method corresponding to traditional learning. Students are the subject of learning, students themselves, not dominated by others, from outside interference, through reading, listening, research, observation and practice so that individuals can be sustained changes in behavior. Language learning is a very complex cognitive development process; foreign language learners must use active and active control of learning means to effectively learn a foreign language. Foreign language learning is an autonomous acquisition process, and learners often need to consciously adjust their own learning methods and learning strategies and other cognitive means to complete the task of learning. Self-study is divided into in-class learning and extra-curricular learning, self-study is to arrange students within the specified time, in the network classroom and group students to prepare activities, check each other learning content; extra-curricular self-study is to guide students in extra-curricular time independent initiative To learn the words and text and other content [7]. Self-regulated learning develops in the following ways: learners identify learning goals, use appropriate learning strategies, monitor their own learning processes, and self-assess academic performance. 
(5) Give fully plays to the role of Chinese knowledge in Japanese teaching. Japanese influenced by Chinese culture, creating favorable conditions for the Chinese to learn Japanese. The emergence and development of Japanese culture is based on Chinese culture, until the eighth century, Japan only through the creation of hiragana and katakana, slowly formed a mature Japanese system. The impact of Chinese culture on Japanese is reflected in four aspects [8]: First, the impact of Japanese pronunciation, Japanese pronunciation of Chinese characters there are three forms, the first is the first from China to Japan Wu sound, the second The second is the impact of the Japanese text, the Japanese hiragana by the evolution of Chinese characters cursive and the Chinese pronunciation of the word is not the same as the Japanese, , The katakana is selected in the Chinese radical regular script; third, the influence of the Japanese text semantics, slangs and idioms is the essence of the Chinese language in Japanese there are many, mostly from the Chinese evolution ; Fourth, the Japanese writing format, the Japanese writing format and form are subject to the impact of Chinese writing. Japanese teachers to Japanese teaching, it is necessary to grasp the Japanese and Chinese links and differences, to play the advantages of the Chinese language is an effective way to quickly improve the Japanese.

\section{Conclusion}

Cognitive approach as dynamic school of foreign language teaching methods exerts a great influence on foreign language teaching and teaching Chinese as a foreign language. The advantage is that according to the students' cognition law to teach, they can adapt to the cognitive psychological process of foreign language learning. They emphasize both teaching and training, and emphasizing the overall understanding of the discourse on the basis of comprehension of single sentence. It is good for training interest and enthusiasm. The shortcoming is that the teaching system is not perfect enough, it does not emphasize the cultivation of students' communicative competence, ignores the role of the learning environment in foreign language teaching, ignores the individual differences among learners, And written language both, do not meet the foreign language teaching practice. In the actual using cognitive methods for Japanese teaching process, we should fully play its advantages, to find ways to avoid shortcomings to improve the effectiveness of Japanese teaching.

\section{References}

[1] Y. Xu, J. X. Huang, "Problems and Countermeasures in Japanese Teaching in China," Journal of Lanzhou Institute of Education, vol. 30, no. 1, pp. 47-48, 2014.

[2] C. Li, "The Application of Cognitive Approach in TCFL," Journal of Hanshan Normal University, vol. 31, no. 1, pp. 100-103, 2010.

[3] Wenfangyuanlin, "Analysis on transformation generative grammar," http://www.360doc.com/content/15/0907/19/18486920_497530978.shtml, 2016-10-2.

[4] Q. Sun, "Using cognitive approach to improve the efficiency of College Foreign Languages Teaching," Journal of Liaoning radio and TV University, vol. 10, no. 1, pp. 27-28, 2005.

[5] J. Z. Li, "The theoretical significance and practical enlightenment of the educational idea of "taking students as the center"," http://dep.gfxy.com/ddk/2010325153715.htm, 2016-10-2.

[6] T. X. Wang, "The difference between 'language use' and 'language competence' and its implications for foreign language teaching," Journal of Lanzhou Institute of Education, vol. 28, no. 4, pp. 73-74, 2012.

[7] Y. Y. Qiu, "On Application of Cognitive Approach in Self-teaching Mode in College English," Journal of Yueyang Vocational and Technical College, vol. 26, no. 3, pp. 38-40, 2011.

[8] Y. J. Chen, "The influence of Chinese culture on Japanese Teaching," Language Planning, vol. 60, no. 18, pp. 15-16, 2015. 